\title{
Laboratory-based investigation of the materials' water activity and pH relative to fungal growth in internally insulated solid masonry walls
}

Jensen, Nickolaj Feldt; Bjarløv, Søren Peter; Rode, Carsten; Andersen, Birgitte; Møller, Eva B.

Published in:

Indoor Air

Link to article, DOI:

10.1111/ina.12796

Publication date:

2021

Document Version

Peer reviewed version

Link back to DTU Orbit

Citation (APA):

Jensen, N. F., Bjarløv, S. P., Rode, C., Andersen, B., \& Møller, E. B. (2021). Laboratory-based investigation of the materials' water activity and $\mathrm{pH}$ relative to fungal growth in internally insulated solid masonry walls. Indoor Air, 31(4), 1252-1266. https://doi.org/10.1111/ina.12796

\section{General rights}

Copyright and moral rights for the publications made accessible in the public portal are retained by the authors and/or other copyright owners and it is a condition of accessing publications that users recognise and abide by the legal requirements associated with these rights.

- Users may download and print one copy of any publication from the public portal for the purpose of private study or research.

- You may not further distribute the material or use it for any profit-making activity or commercial gain

- You may freely distribute the URL identifying the publication in the public portal 
1 Laboratory based investigation of the materials' water activity and $\mathrm{pH}$ relative to fungal growth in

2 internally insulated solid masonry walls

3 Jensen et al.

4 Nickolaj Feldt Jensen ${ }^{1, *}$, Søren Peter Bjarløv ${ }^{1}$, Carsten Rode ${ }^{1}$, Birgitte Andersen², Eva B.

5 Møller $^{1}$

\section{Acknowledgments}

7 This research was financially supported by Grundejernes Investeringsfond (The Landowners'

8 Investment Foundation), and the European Union's Horizon 2020 research and innovation

9 programme under grant agreement No 637268 - as part of the RIBuild project. None of the

10 authors conflict of interest to declare.

\section{Abstract}

12 This project investigated fungal growth conditions in artificially contaminated interfaces 13 between solid masonry and adhesive mortar for internal insulation. The project comprised 14 several laboratory experiments: test of three fungal decontamination methods; investigation of 15 development of fungal growth in solid masonry walls fitted with five internal insulation 16 systems; and investigation of Volatile Organic Compounds (VOC) diffusion through materials 17 and whole insulation systems. One aim was to examine whether the alkaline environment $(\mathrm{pH}>$ $189)$ in the adhesive mortars could prevent fungal growth despite the water activity $\left(a_{w}\right)$ in the 19 interface exceeds the level $\left(a_{w}>0.75\right)$ commonly considered critical for fungal growth. The

\footnotetext{
${ }^{1}$ Department of Civil Engineering, Technical University of Denmark, Brovej 118, 2800 Kgs. Lyngby, Denmark

${ }^{2}$ Department of Bioengineering, Technical University of Denmark, Søltoft Plads Building 221, 2800 Kgs. Lyngby, Denmark

*Corresponding author.

E-mail addresses: nicf@byg.dtu.dk (Nickolaj Feldt Jensen).
} 
20 findings indicate that do-it-yourself decontamination solutions were inadequate for removal of

21 fungal growth, while professional solutions were successful. However, the choice of

22 decontamination method was of minor importance in the case of application of internal

23 insulation with high $\mathrm{pH}$ adhesive mortar, as the high $\mathrm{pH}$ adhesive mortars were found to

24 inactivate existing growth and prevented spore germination during the experimental period. The

25 three tested VOCs were capable of diffusing through most of the examined products and could

26 potentially affect the indoor air quality.

27 Keywords: internal insulation, solid masonry walls, laboratory study, mould growth, mould 28 decontamination methods, material alkalinity

\section{Practical Implications:}

- The risk of fungal growth in the interface between the masonry wall and added internal insulation is reduced considerably if high $\mathrm{pH}(12+)$ adhesive mortar is used during the application of the system.

- For fungal decontamination purposes the two professional methods are preferred, however, if followed by application of internal insulation with high $\mathrm{pH}$ adhesive mortar, the choice of decontamination method is of minor importance. The impact of not removing organic matter and fungal growth before application of insulation systems with high $\mathrm{pH}$ adhesive mortar is yet to be determined.

- Fungal mycelium is inactivated by the high $\mathrm{pH}$ in the adhesive mortar, but the fungal spores remain dormant and can germinate if $\mathrm{pH}$ in the construction drops to more favourable levels which could lead to new fungal growth.

- Typical VOCs produced by fungal growth can be transported to the indoor climate by diffusion through interior insulation. The permeability towards VOCs correlates with the water vapour permeability, i.e. diffusion of VOCs to the indoor environment is reduced with increased water vapour diffusion resistance of the insulation system. 
46

47

48

49

50

51

52

53

54

55

56

57

58

59

60

61

62

63

64

65

66

67

68

One effective measure of energy conservation in the European building stock is retrofitting the external walls ${ }^{1} .41 \%$ of all existing multi-story residential buildings in Denmark (3+ floors) were constructed during the period $1850-1930$, with solid masonry external walls ${ }^{2}$ having an average-weighted $\mathrm{U}$-value of $0.62 \mathrm{~W} / \mathrm{m}^{2} \cdot \mathrm{K}$ for the external walls ${ }^{1}$, which indicate a large potential for energy conservation. External insulation is considered the more feasible solution for retrofitting solid masonry walls compared to internal insulation as it is safer in terms of moisture related issues, more efficient for reduction of heat losses through the envelope, and protects the existing wall structure against the outdoor climate ${ }^{3-6}$. However, external retrofitting is not always possible for historic buildings if their external appearance is worthy of preservation.

There exists a great deal of scepticism regarding the use of internal insulation, as it in the past have resulted in many cases with mould growth (fungal growth) occurring between the existing wall structure and the insulation system ${ }^{4}$. One of the main problems is that internal insulation causes the existing masonry wall to become colder ${ }^{6}$, which in turn increases the risk of interstitial condensation ${ }^{3,7}$. The added insulation system will also increase the diffusion resistance between the existing wall and the room, which reduces the inward moisture diffusion that contributes to drying of the wall ${ }^{7,8}$. In addition, there is risk of summer condensation in periods with alternating rainfalls and solar exposure ${ }^{3,4}$. Insulation systems introduced on the market over the past two decades have tried to overcome these issues through the use of diffusion-open insulation materials with capillary active properties $5,9,10$. These systems allow capillary moisture redistribution in an attempt to avoid unacceptably high moisture levels in critical locations. Previous research does not fully agree on the performance of the diffusionopen capillary active systems. Good performance was observed in a number of studies ${ }^{5,8,11-13}$, 
while other studies ${ }^{14,15}$ found potentially critical Relative Humidity (RH) levels in critical locations such as in the masonry/insulation interface or in embedded wooden elements.

Several systems for internal retrofitting solid masonry walls comprise an insulation material and an adhesive mortar, and according to the manufacturers these systems prevent fungal growth from occurring by combining inorganic insulation with a highly alkaline adhesive mortar $(\mathrm{pH}>12)$ to create an unfavourable environment where fungi cannot survive even if $\mathrm{RH}$ is higher than what is normally considered to be acceptable at the given temperature. The optimum environment for most fungal species is between $\mathrm{pH} 4$ and 9 , and prevention of fungal growth could potentially be achieved by creating a less favourable $\mathrm{pH}$ environment ${ }^{16}$. Investigations by Morelli \& Møller ${ }^{13}$ and Jensen et al. ${ }^{17}$ found no fungal growth behind internal insulation with adhesive mortar of high $\mathrm{pH}$ after several years despite of high water activities.

Several studies have shown difficulties maintaining non-critical RH levels in the interface and in embedded wooden elements of internally insulated solid masonry walls, so the structures must be secured against fungal growth in other ways. This could be done by ensuring that all organic residues (e.g. from glue and wallpaper) are removed prior to installation of the insulation system, since fungi need very little nourishment and can grow even on dirt and dust. Another option is to apply fungicides before installation, but this might create problems for the indoor climate. Exposure to pesticides, including fungicides, may result in short-term skin and eye irritation, dizziness, headaches, and nausea, while long-term effects may include increased risk of cancer, asthma ${ }^{18}$ and damage to central nervous system and kidney ${ }^{19}$.

The purpose of this project was to study the effect of alkaline $(\mathrm{pH}>9)$ adhesive mortar joint between existing wall and installed insulation would be sufficient to prevent fungal growth, when the moisture level (water activity $\left(a_{w}\right)$ ) in the interface exceeds 0.75 , which is considered critical for fungal growth at room temperature ${ }^{3}$. The study also tested the effectiveness of different fungal decontamination methods. Diffusion of Volatile Organic Compounds (VOCs) 
94 through the insulation systems was also tested to determine if VOCs, known to be produced 95 during fungal growth, could enter the indoor environment if fungal growth should occur behind 96 the internal insulation.

\section{Methods and materials}

98 The present study was performed in four main steps:

1) Preparation of the experimental setup, Section 2.2

2) Experiment 1: Test of decontamination methods, Section 2.4

3) Experiment 2: Development of fungal growth in interface, Section 2.5

The following sections will describe the activities under each step in more detail, and Figure 1 shows the activities carried out in relation to the two consecutive experiments with the masonry masonry specimens (experiment 1 and 2), and in the VOC diffusion experiment.

\subsection{Investigated insulation systems and preliminary material tests}

Five different insulation systems were tested for fungal growth on masonry specimens: 1) Calcium silicate (Casi), 2) Autoclaved aerated concrete (AAC), 3) Composite material of polyurethane foam with calcium silicate channels (PUR-CM), 4) Phenolic resin foam with an aluminium foil (Phenolic), and 5) insulating plaster composed of cork granulate, silica filler, natural volcanic materials and Natural Hydraulic Lime (NHL) (Cork plaster). Except for the cork plaster all systems included an adhesive mortar. The build-up of the masonry specimens

113 and the five insulation systems are shown in Table 1, which also includes material properties, 114 these were determined in the preliminary study or provided by the manufacturers.

115 A preliminary study was performed to determine the water vapour diffusion resistance, water 116 absorption by capillary action, density, and $\mathrm{pH}$-value for the used adhesive mortars and the 
117 Cork plaster. Density was determined according to the LBM test method $2{ }^{20}$. The water vapour

118 diffusion resistance factor, $\mu$ was determined through wet cup test (Set C) according to DS/EN

119 ISO $12572{ }^{21}$. Three $\varnothing 80 \mathrm{~mm}$ samples of each product were tested, with a thickness of $10 \mathrm{~mm}$

120 for the adhesive mortars, and $30 \mathrm{~mm}$ for the Cork plaster. The water absorption by capillary

121 action was determined through partial immersion according to DS/EN ISO 15148:2003 ${ }^{22}$.

122 Three samples of each product were tested, with a total contact surface of approximately 300

$123 \mathrm{~cm}^{2}$. The $\mathrm{pH}$-value was determined for the adhesive mortars, 7.7\% lime adjusted mortar, and

124 Cork plaster. Samples were crushed into powder, and $5 \mathrm{~g}$ was mixed with $12.5 \mathrm{ml}$ demineralized

125 water. Samples were shaken for 60 minutes at 260-270 rpm, followed by a 10 minutes settling

126 period before testing. The $\mathrm{pH}$ measurements were performed using a HACH Sension+ MM 374

127 GLP 2 channel Laboratory Meter for $\mathrm{pH}$ (accuracy: $\leq 0.002 \mathrm{pH}$ ).

\section{$128 \quad 2.2$ Description of the experimental setup used in experiments 1 and 2}

129 The experimental setup comprised 17 small masonry masonry specimens with dimensions

$130(\mathrm{~L} \times \mathrm{W} \times \mathrm{H}): 350 \mathrm{~mm} \times 350 \mathrm{~mm} \times 180 \mathrm{~mm}$ (including $10 \mathrm{~mm}$ internal render). The masonry

131 specimens were constructed in 2015 (four years before this study began) from yellow soft-

132 moulded bricks and 7.7\% lime adjusted mortar resembling the materials used in Danish historic

133 buildings from 1850-1930. The lime adjusted mortar was also used as internal render. The

134 mortar joints were assumed fully carbonated prior to the present study.

135 The masonry specimens were inserted over a water vessel (small box of $600 \mathrm{~mm} \times 400 \mathrm{~mm} \times$

$136100 \mathrm{~mm})$ within a larger box $(780 \mathrm{~mm} \times 560 \mathrm{~mm} \times 440 \mathrm{~mm})$ (Figure 2). The small box

137 contained a plastic grate to keep the masonry specimen above the demineralized water inside

138 the box and a hole was made in the box lid to fit the masonry specimen, while the large box

139 was used to emulate an indoor climate however without conditioning. Prior to the experiments,

140 each masonry specimen was sealed on the vertical sides using a primer and wet room membrane

141 (red lines in Figure 2). The joints between the vertical sides of the masonry specimen and box 
142 lid were sealed using silicone sealant, while the joints between box and lid were sealed using

143 vapour barrier tape. An $\varnothing 100 \mathrm{~mm}$ hole was made in the lid to refill water into the small box,

144 and the opening was sealed using a rubber plug. The joints between the large box and its lid

145 were sealed using rubber sealing strips and secured using tightening clamps. The indoor climate

146 of the test facility (outside the large outer box) was kept at $20{ }^{\circ} \mathrm{C}$, with $\mathrm{RH}$ between 30 and

$14760 \%$. The desired RH in the masonry/insulation interface was $>96 \%$, which should ensure

148 favourable moisture levels for fungal growth. The experiments were carried out as isothermal.

149 With this experimental setup two experiments were carried out consecutively: 1) Test of

150 decontamination methods; and 2) Development of fungal growth in interface (see Figure 1).

151 Temperature and RH were measured manually every two weeks throughout both experimental 152 periods using digital HYT221 sensors by Innovative Sensor Technology IST AG, calibrated 153 prior to installation. Sensors were installed inside the large box during the fungal 154 decontamination experiment, and later also in the interface between the masonry specimen and 155 insulation system for the fungal growth experiment. Two sensors were installed for the indoor 156 climate of test facility. The accuracy of the sensors was $0.2 \mathrm{~K}$ at 0 to $60{ }^{\circ} \mathrm{C}$ for temperature, and $1571.8 \%$ at $23{ }^{\circ} \mathrm{C}$ at 0 to $90 \%$ for $\mathrm{RH}$ and $2-4 \%$ above $90 \% \mathrm{RH}$. The sensor range was -40 to 125 $158{ }^{\circ} \mathrm{C}$ for temperature, and 1 to $100 \%$ for $\mathrm{RH}$.

$159 \quad 2.3 \quad$ Test procedures to determine the presence of fungal growth in experiments 1 and 2

160 The presence of fungal growth in experiments 1 and 2 was investigated with: 1) The Mycometer 161 method; and 2) Agar imprint test. The sampling method and the test procedures are described 162 below.

163 Sampling method: Fungal surface sampling in experiment 1 was carried out through swabbing 164 using sterile cotton buds, as described for the Mycometer Surface test below. Fungal sampling 165 of the masonry specimens in experiment 2 was carried out by drilling two core samples of the 
166 interior insulation system (including adhesive mortar and internal lime render) from each

167 masonry specimen using an $\varnothing 80 \mathrm{~mm}$ hole-saw without the pilot bit (Figure 3a). The samples

168 were placed in sealed containers immediately after fungal- and material specimens were taken

169 in the masonry/insulation interface and the hole-saw was disinfected with ethanol $96 \%$ between

170 drillings to avoid contamination.

171 The Mycometer method: The amount of fungal biomass (living and dead) was assessed

172 quantitatively using the Mycometer method ${ }^{23}$. The method determined the amount of fungal

173 growth by measuring the fluorescent product released from the enzyme-substrate complex

174 relating to the $\mathrm{N}$-acetylhexosaminidase activity found in the mycelium and spores, expressed

175 by a Mycometer value. Two types of Mycometer tests were carried out: 1) The Mycometer

176 Surface test ${ }^{24}$; and 2) The Mycometer Bulk-material test ${ }^{25}$.

177 The Mycometer Surface test was used to assess the effectiveness of the fungal decontamination

178 work in experiment 1 and later to determine the extent of the fungal growth in the 179 masonry/insulation interface in experiment 2. The surface sampling was done through 180 swabbing, using sterile cotton buds, within a measurement area of $9 \mathrm{~cm}^{2}$ (see Figure $3 \mathrm{~b}$ ).

181 The Mycometer Bulk-material test was used to evaluate growth in the adhesive mortars and 182 determine growth in different layers of the insulation system. In the laboratory the $\emptyset 80 \mathrm{~mm}$ 183 drilling cores were disassembled and prepared for the bulk material test (see Figure $3 \mathrm{~d}$ ). The 184 outer parts (excess insulation and internal finishing layer) were cut away, and the central part 185 of the drilling core was divided into three sections (the outermost $10 \mathrm{~mm}$ of insulation i.e. 186 closest to the masonry wall, and the remaining insulation thickness was divided in two equal 187 sized sections). The three sections were crushed into powder so was a section of the adhesive 188 mortar, $100 \mathrm{mg}$ of each was used for the bulk material test. The bulk material tests were 189 performed for the middle and innermost sections of the drilling core only if growth was detected 190 in the outermost section, as previous experience ${ }^{17}$ with the bulk material test have shown that 
191 if no fungal growth is found in the interface or in the outermost section of the material sample

192 then growth are improbable in the middle and innermost sections. In each of the two sampling 193 rounds (after 6 and 12 months) in experiment 2, two samples were tested for the 194 masonry/insulation interface, and two for each of the insulation layers tested in the bulk material 195 test.

196 The Mycometer values obtained were evaluated as; Category A (green), normal background 197 level: $\mathrm{MV} \leq 25$ (surface) or $\mathrm{MV} \leq 150$ (bulk material), Category B (yellow), above normal 198 background level: $25<\mathrm{MV}<450$ (surface) or $150<\mathrm{MV}<450$ (bulk material), and Category $199 \mathrm{C}$ (red), high level of fungi: MV $>450$.

200 The accuracy of the Mycometer method was evaluated by the US EPA ${ }^{26}$ who found that the 201 relative standard deviation was around 5-10\% for tests performed with fungal spores from 202 Aspergillus flavus and Cladosporium herbarum.

203 Agar imprint test: A qualitative assessment of the fungal growth was performed through 204 cultivation on agar media (Dichloran 18\% Glycerol agar (DG18) and Original V8 Vegetable 205 Juice agar (V8) ${ }^{27}$, allowing for identification of fungal species. The agar imprint test was 206 carried out only in experiment 2. Following the Mycometer Surface swab tests for the 207 masonry/insulation interface, the interface side of the drilling core was pressed down onto V8 208 and DG18 media (see Figure 3c). The media was incubated at $25{ }^{\circ} \mathrm{C}$ in darkness for 7 days and 209 fungal colonies were identified under stereo- and light microscope ${ }^{27}$.

\section{$210 \quad 2.4$ Experiment 1: Decontamination methods}

\section{$211 \quad 2.4 .1 \quad$ Artificial inoculation of masonry specimens}

212 For experiments 1 and 2 the masonry specimens were artificially inoculated with a mixture of 213 spores from four common indoor climate fungal species from the Fungal Culture Collection at 214 DTU Bioengineering: Acremonium murorum (IBT 42592), Aspergillus versicolor (IBT 33558), 
216 requirements for growth.

217 For this experiment 12 of the 17 masonry masonry specimens were used, four specimens for 218 each of the three decontamination methods, while the remaining 5 masonry specimens were left 219 out of experiment 1 and were to be used only in experiment 2 as "un-inoculated" reference 220 walls. The 12 "decontaminated" masonry specimens would be re-used in experiment 2 to 221 investigate if the choice of decontamination method had any effect on fungal growth in the 222 masonry/insulation interface after application of the internal insulation systems. Woodchip 223 wallpaper was applied to all 12 masonry specimens using wallpaper glue based on potato starch 224 mixed with the fungal spore mixture stated above. The spore concentration in the finished glue 225 mix was approximately $10^{5}$ spores per $\mathrm{mL}$ for each fungal species. The small boxes containing 226 the masonry specimens were placed inside the large boxes (Figure 2a) and demineralised water 227 was added to the small boxes. The inoculated masonry specimens were then left for seven 228 weeks.

\section{$229 \quad 2.4 .2$ Decontamination of masonry specimens}

230 The masonry specimens were cleaned for organic residues and fungal growth using following 231 methods: 1) Hand-power: manual removal of wallpaper with a paint scraper (Figure 4a), 2) 232 Mechanical: manual removal of wallpaper and internal render with hammer and chisel (Figure 4b), and application of new render layer, and 3) MicroClean: removal of wallpaper with a paint

234 scraper, and decontaminated using the MicroClean method ${ }^{28}$ according to manual and 235 performed by professionals (Figure 4c-d). The MicroClean decontamination was performed in 236 four steps: 1) Vacuum the infected surface; 2) Dry-steam cleaning at $150-160{ }^{\circ} \mathrm{C}$, using plate 237 mouth piece with a steam pressure of 8 atm; 3) Dry-steam cleaning with fibred cotton cloth 238 mouth piece, with simultaneous vacuuming of denatured dissolved biomass. The cotton cloths 239 were changed continually as they became saturated with moisture and biomass; and 4) Vacuum 
240 the surface. All boxes were disinfected using fungal disinfection agents. After decontamination

241 of masonry specimens and boxes, the setup was reassembled as shown in Figure 2a.

\section{$242 \quad$ 2.4.3 Surface analysis for fungal growth}

243 After 14 days the effectiveness of the decontamination methods was assessed with Mycometer

244 Surface tests, with two samples for each masonry specimen. For the mechanical method the

245 Mycometer Surface tests were taken on top of the new internal render layer.

\section{$246 \quad 2.5 \quad$ Experiment 2: Development of fungal growth in interface}

\section{$247 \quad 2.5 .1 \quad$ Artificial inoculation of masonry specimens}

248 One $\mathrm{mL}$ of spore suspension containing the fungal species described in Section 2.4.1, 249 (approximately $10^{6}$ spores per $\mathrm{mL}$ of each species) was placed in the centre of the interface 250 surface area of each of the 12 decontaminated masonry specimens and the 5 masonry 251 specimens, which were un-inoculated in experiment 1.

\section{$252 \quad$ 2.5.2 Application of the insulation systems}

253 After application of the spore suspension on all 17 masonry specimens, the CaSi, AAC, PUR-

$254 \mathrm{CM}$, and Phenolic systems were installed according to the manufactures instructions, starting

255 with adhesive mortar. The four systems were installed on 16 of the masonry specimens so that 256 each system would be installed for each of the three decontamination methods and on the un257 inoculated masonry specimens (see Figure 5). On the $17^{\text {th }}$ masonry specimen, the Cork plaster 258 was installed.

259 After installation, the small boxes containing the insulated wall specimens were placed back in 260 the large boxes, and water was again added to the small boxes representing the wet climate 261 (Figure 2b). Due to issues reaching the desired RH levels in the interface of the masonry 262 specimens fitted with Phenolic insulation, a $25 \mathrm{~W}$ aquarium heater was installed in the small 
263 box two months after experiment start in order to increase the water vapour pressure by raising

264 the water temperature to $24^{\circ} \mathrm{C}$.

\section{2.5.3 Surface and material analyses for fungal growth, $\mathrm{pH}$ and moisture content}

266 After 6 and 12 months drilling cores were taken out at the centre of the walls and $15 \mathrm{~cm}$ to the 267 side of the centre, respectively, and fungal growth and material samples were taken for analysis

268 according to the procedures in Sections 2.1 and 2.3. The moisture content was determined for 269 the interface materials and in the outermost $10 \mathrm{~mm}$ of the insulation through weighing and 270 drying.

\section{$271 \quad 2.6 \quad$ Experiment 3: VOC diffusion}

272 In the experiments described in this section only the insulation materials and corresponding 273 adhesive mortars, finishing layers and membranes were used. Possible diffusion of Volatile 274 Organic Compounds (VOCs) through the materials making up the examined insulation systems 275 were investigated using acetone (CAS-number: 67-64-1 (Matas A/S, Denmark)), ethanol (CAS276 number: 64-17-5 (VWR International)), and 2-heptanone (CAS-number: 110-43-0 (Merck Life 277 Science A/S, Denmark)), to mimic the VOCs produced by common indoor fungi ${ }^{29}$. The 278 experiment was carried out similar to the cup method for determination of the water vapour 279 diffusion resistance factor according to DS/EN ISO $12572^{21}$. Three $\varnothing 80 \mathrm{~mm}$ samples of each 280 insulation systems were tested, which were the adhesives, insulation materials, renders, and 281 membranes. Insulation material samples had a thickness of $30 \mathrm{~mm}$, render and adhesives 282 samples $10 \mathrm{~mm}$, and gypsum board with aluminium foil samples $13 \mathrm{~mm}$. Each sample was 283 sealed on the sides using epoxy, which was cast around the sample while placed inside a PVC 284 ring ${ }^{30}$. In contrast to the water vapour diffusion experiment, the cups were filled with one of 285 the aforementioned solvents which diffused through the product samples due to a difference in 286 the vapour pressure. The cups were weighted periodically, and the results were evaluated 
287 through linear correlation between time and weight loss. The experiment was ended after 288 obtaining a $\mathrm{R}^{2}$ value of minimum 0.97 in relation to the linear weight changes. The results were 289 corrected for variations in the barometric pressure during the tests.

290 The temperature and RH conditions inside the fume hood during the each of test rounds for the 291 VOC diffusion experiment ranged from 20 to $22{ }^{\circ} \mathrm{C}$ and the $\mathrm{RH}$ levels from 30 to $45 \%$. The 292 vapour pressure differences over the material samples were calculated using the measured 293 temperatures during each of the test rounds and assuming vapour saturation inside the test cups 294 and no VOC present in the ambient air. The resulting pressure differences were around 26000, 2956300 , and $155 \mathrm{~Pa}$ respectively for acetone, ethanol and 2-heptanone. The saturation vapour 296 pressures were determined using the Antoine equation ${ }^{31}$.

297 Based on the VOC diffusion experiment, the project adopted the similarity approach for 298 modelling the transport of moisture VOCs in materials presented by Rode et al. in ${ }^{32}$, where the 299 diffusion similarity factor, $\kappa_{d i f f, v o c}[-]$ were determined according to equations $1-3$. A $\kappa_{d i f f, v o c}$ 300 of 1 means that the material has equal diffusion resistance factors for diffusion of VOC as for 301 water vapour, where the diffusion resistance factor is defined as the diffusion coefficient of the 302 gas in still air divided by the diffusion coefficient of the same gas through the porous material.

$303 \kappa_{\text {diff }, v o c}=\frac{\mu_{v o c}}{\mu_{v}}$

$304 \quad \mu_{v o c}=\frac{D_{v o c, a i r}}{D_{e}}$

$305 D_{e}=D_{p} \cdot R_{g a s} \cdot T$

306 Where,

$307>\mu_{v o c}$ and $\mu_{v}$ are the diffusion resistance factors for VOC and water vapour [-]

$308>D_{\text {voc,air }}$ is the diffusion coefficient of a VOC in air $\left[\mathrm{m}^{2} / \mathrm{s}\right]$ : acetone $1.24 \mathrm{E}-05$, ethanol 309 1.15E-05, 2-heptanone 6.24E-06, and water vapour $2.64 \mathrm{E}-05 \mathrm{~m}^{2} / \mathrm{s}$. 
$>D_{e}$ is the diffusion coefficient $\left[\mathrm{m}^{2} / \mathrm{s}\right]$ of the material based on vapour content by volume in unit $\mathrm{kg} / \mathrm{m}^{3}$.

312

$>D_{p}$ is the diffusion coefficient $[\mathrm{kg} /(\mathrm{m} \cdot \mathrm{s} \cdot \mathrm{Pa})]$ of the material based on vapour pressure, derived from the VOC diffusion measurements.

$>R_{\text {gas }}$ is the specific gas constant $[\mathrm{J} /(\mathrm{kg} \cdot \mathrm{K})]$ : acetone 143.2 , ethanol 180.5, 2-heptanone 72.8 , and water vapour $461.4 \mathrm{~J} / \mathrm{kg} \cdot \mathrm{K}$.

$T$ is the temperature in the VOC diffusion experiment, of $294.5 \mathrm{~K}$.

$317 \kappa_{d i f f, v o c}$ was determined for the four adhesive mortars, the cork plaster and gypsum board.

\section{$\begin{array}{lll}318 & 2.7 & \text { Theoretical VOC mass balance for a room scenario }\end{array}$}

319 A VOC mass balance was established for a hypothetical $27 \mathrm{~m}^{3}$ room scenario with an Air 320 Change per Hour ( $\mathrm{ACH}$ ) of $0.5 \mathrm{~h}^{-1}$ (in accordance with local regulations) to calculate the VOC content in the room air in the case of $1 \mathrm{~m}^{2}$ of fungal growth behind the examined insulation

322 systems. The VOC saturation pressures stated in Section 2.6 were assumed, and the diffusion 323 resistance of the systems were obtained from the VOC diffusion experiment. The VOC content 324 in the room air was calculated with equations 4-10:

325 The VOC mass balance for the room:

$326 G_{v o c, \text { entering }}+G_{v o c, p}=G_{v o c, \text { leaving }} \Leftrightarrow x_{v o c, e} \cdot G_{a}+G_{v o c, p}=x_{v o c, i} \cdot G_{a}$

$327 \quad G_{a}=\frac{q \cdot \rho_{a, i}}{3600}$

328 Adding the mass flow of air, $G_{a}[\mathrm{~kg} / \mathrm{s}]$ to the equation and solving for $X_{v o c, i}$ :

$329 x_{v o c, e} \cdot \frac{q \cdot \rho_{a, i}}{3600}+G_{v o c, p}=x_{v o c, i} \cdot \frac{q \cdot \rho_{a, i}}{3600} \Leftrightarrow x_{v o c, i}=\frac{\left(\frac{q \cdot \rho_{a, i}}{3600}\right) \cdot x_{v o c, e}+G_{v o c, p}}{\frac{q \cdot \rho_{a, i}}{3600}}$

330 Assuming the sovent concentration in the outdoor air to be 0 , then we get:

$331 \quad x_{v o c, i}=\frac{\left(\frac{q \cdot \rho_{a, i}}{3600}\right) \cdot 0+G_{v o c, p}}{\frac{q \cdot \rho_{a, i}}{3600}} \Leftrightarrow x_{v o c, i}=\frac{G_{v o c, p}}{\frac{q \cdot \rho_{a, i}}{3600}}$ 
334 The VOC vapour pressure in the room air, $P_{v o c, i}$, was solved iteratively by:

$$
x_{v o c, i}=\frac{m_{v o c}}{m_{\text {air }}}=\frac{p_{v o c, i} \cdot M_{v o c}}{\left(P-p_{v o c, i}\right) \cdot M_{a i r}} \cong \frac{p_{v o c, i} \cdot M_{v o c}}{\left(M_{\text {air }} \cdot P\right)} \Leftrightarrow P_{v o c, i}=\frac{x_{v o c, i}}{\left(\frac{p_{v o c, i} \cdot M_{v o c}}{\left(M_{\text {air }} \cdot P\right)}\right)}
$$

336 Where,

$337>G_{v o c, \text { entering }}$ and $G_{v o c, \text { leaving }}$ are the VOC vapour entering and leaving the room [kg/s]

$338>G_{v o c, p}$ is the VOC vapour penetrating the insulation system in $[\mathrm{kg} / \mathrm{s}]$

$339>x_{v o c, e}$ and $x_{v o c, i}$ are the VOC vapour ratio in the outdoor and room air $[\mathrm{kg} / \mathrm{kg}]$

$340>q$ is the ventilation flow $\left[\mathrm{m}^{3} / \mathrm{h}\right]$, which is the product of the room volume and the

$341 \quad \mathrm{ACH}$.

$342>\rho_{a, i}$ is the density of the room air $\left[\mathrm{kg} / \mathrm{m}^{3}\right]$, at $21.3{ }^{\circ} \mathrm{C}$

$343>p_{\text {voc,fungal }}$ is the VOC saturation pressure behind the insulation system [Pa]

$344>p_{v o c, i}$ is the VOC vapour pressure in the room air $[\mathrm{Pa}]$

$345>P$ is the atmospheric pressure $101325 \mathrm{~Pa}$

$346>Z$ is diffusion resistance of insulation systems $\left[\mathrm{m}^{2} \cdot \mathrm{s} \cdot \mathrm{Pa} / \mathrm{kg}\right]$

$347>A$ is the assumed fungal growth area behind the insulation system $\left[\mathrm{m}^{2}\right]$

$348>v_{v o c, i}$ is the VOC vapour content in the room air $\left[\mathrm{kg} / \mathrm{m}^{3}\right]$

$349>m_{v o c}$ and $m_{\text {air }}$ are the mass of the VOCs and of dry air respectively [kg]

$350>M_{v o c}$ is the molar mass of the solvents $[\mathrm{g} / \mathrm{mol}] ; 58.08,46.07$ and $114.19 \mathrm{~g} / \mathrm{mol}$

351 respectively for acetone, ethanol, and 2-heptanone

$352>M_{\text {air }}$ is the molar mass of dry air $[\mathrm{g} / \mathrm{mol}] ; 28.96 \mathrm{~g} / \mathrm{mol}$ 


\section{$353 \quad 3 \quad$ Results}

\section{$354 \quad 3.1 \quad$ Experiment 1: Decontamination methods}

355 The results of decontamination methods show high levels of fungal growth in all masonry 356 specimens using the "hand-power" decontamination method with the paint scraper (Table 2).

357 For one wall using the Microclean method it was found that the Mycometer Surface Value 358 (MSV) results were just above background level. Results from the remaining masonry 359 specimens were within normal background level.

\subsection{Experiment 2: Development of fungal growth}

\section{$361 \quad$ 3.2.1 Hygrothermal measurements}

362 Results show that the average temperatures in the interface between the masonry specimens 363 and insulation systems were between 18.4 and $19.5^{\circ} \mathrm{C}$, except for the walls with Phenolic foam 364 where temperatures ranged from 20.6 to $22.7^{\circ} \mathrm{C}$ due to the aquarium heaters. The average $a_{w}$ 365 in the interface were between 0.99 and 0.999 for all masonry specimens except the four 366 Phenolic walls (where three were around $a_{w}$ 0.86-0.88 and one at at 0.964) and one CaSi wall 367 (at $a_{w}$ 0.959). The final $a_{w}$ were between 0.995 and 0.999 for all walls except for three of the 368 four Phenolic walls, which varied from 0.934 to 0972 . The final moisture content for the

369 adhesive mortars and insulation materials are listed in Table 3. The measured hygrothermal 370 conditions for the interface were considered very favourable for the occurance of fungal growth 3713.

\section{$372 \quad 3.2 .2 \quad \mathrm{pH}$ and fungal growth testing}

373 The result of the material tests performed after one year of application showed that the internal 374 renders had $\mathrm{pH}$-values of 12.2 to 12.6 , and the adhesive mortars from 12.4 to 12.7 . 
375 The Mycometer surface and bulk material tests for all the 17 masonry specimens showed that

376 the fungal biomass was below background levels, which was the case for both fungal sampling

377 rounds (after 6 and 12 months), see Table 4. In contrast to the Mycometer tests, the agar imprints

378 of the drilled-out core samples found viable spores present in the interface of nearly all masonry

379 specimens. Primarily Aspergillus versicolor and Penicillium chrysogenum colonies were found

380 after transference to the agar media, with the vast majority of the viable spores being $A$.

381 versicolor. None or few viable Acremonium murorum and Wallemia sebi spores were found

382 after transference to the agar media. Comparison of the core samples from the different

383 insulation systems showed a significantly larger number of viable spores in the interface of the

384 Phenolic system compared to the other systems. A comparison between the two sampling

385 rounds showed differences in the amount of viable spores, and in some corner samples (round

386 2) the spore count was higher than the central samples (round 1) where the spore suspension

387 was placed originally. No differences were seen between insulation systems or the

388 decontamination methods.

\section{$389 \quad 3.3 \quad$ Experiment 3: VOC diffusion}

390 The VOC vapour flow rate density of the examined material samples are presented in Figure 6, 391 and the derived permeability values are available in ${ }^{30}$. It was seen that the vapour flow rate 392 density of acetone was 5-6 times higher than that of ethanol, 27-28 times higher than water, and 393 55-57 times higher than 2-heptanone. For ethanol the vapour flow rate density was 5 times 394 higher than that of water, while for 2-heptanone the vapour flow rate density was $40 \%$ lower 395 than water. The diffusion similarity factor, $\kappa_{d i f f, v o c}$ for acetone, ethanol and 2-heptanone 396 determined through the similarity approach are shown for the six examined materials in Figure

397 7. The average $\kappa_{\text {diff, voc }}$ values for the three VOCs were 1.16, 1.21 and 0.35 respectively.

398 The vapour diffusion resistance, $Z$, for the five systems based on the derived permeability values 399 in ${ }^{30}$ and the system configurations (Table 1) are listed in Table 5. It was observed that the 
Phenolic and PUR-CM systems were considerably more diffusion tight against VOC transport compared to the $\mathrm{CaSi}, \mathrm{AAC}$ and Cork plaster systems. In the case that the fungal growth was to occur in the interface between the adhesive mortar and insulation instead of between the internal lime render and adhesive, the diffusion resistance of the insulation system against transport of the examined VOCs decreases by: PUR-CM 1.3-3.7\%; CaSi 25.4-27\%; AAC 12.8$13.6 \%$, and Phenolic $<0.3 \%$.

\subsection{Theoretical VOC mass balance for a room scenario}

Table 6 shows the VOC vapour content in the room air obtained through the VOC mass balance calculations for three VOCs and the five insulation systems. It was seen that the VOC content in the room air was higher for the $\mathrm{CaSi}, \mathrm{AAC}$ and Cork plaster systems compared with the tighter PUR-CM and Phenolic systems. In addition, the VOC content in the room air seemed to be higher in the case of the more volatile acetone.

\section{Discussion}

\subsection{Experiment 1: Decontamination methods}

In the experiment with the three decontamination methods it was found that the simple handpower method using a paint scraper was insufficient for removal of all fungal biomass (spores and mycelium) on the masonry specimens. This was probably due to the hand-power method only removed fungal mycelium and spores in/on the wallpaper and glue, while the mycelium penetrating into the internal render layer would remain. In one masonry specimen a high level of fungal biomass using the Mycometer test was found in one location, and below detection range in another, which suggest an uneven distribution of growth or effectiveness of the handpower decontamination of the wall surface. It also highlights the importance of performing several and different tests (agar growth and Mycometer). In contrast to the hand-power method, the mechanical method with hammer and chisel was found to be very effective as it also 
424 removed potential growth in the internal render layer. For the MicroClean method, it was found

425 that the Mycometer Surface results were below normal background level, which indicates that 426 the heat treatment with dry steam was effective at removing of fungal growth on the masonry 427 specimens.

\section{$428 \quad 4.2$ Experiment 2: Development of fungal growth}

429 In the experiment with added insulation systems no active fungal growth was found in the 430 interface between the masonry specimens and the insulation systems despite favourable 431 temperature and $a_{w}$ and the presence of fungal spores. The lack of fungal growth as tested with

432 the Mycometer method was probably due to the high $\mathrm{pH}$ of the internal render and the adhesive 433 mortars, which seemed to hamper germination and growth, as concluded in ${ }^{13,17}$. On the other 434 hand, as a result of the agar imprint tests it was found that large numbers of A. versicolor and 435 P. chrysogenum spores survived the high $\mathrm{pH}$ in the interface and formed colonies when 436 transferred to V8 and DG18 agar. The spores were seen to survive better in the adhesive mortar

437 used for the Phenolic system compared to the other adhesive mortars despite similar pH levels.

438 The results indicate that the moisture weight- $\%$ in the adhesive mortars could be an important 439 factor in terms of the amount of surviving fungal spores in the interface, where the four Phenolic 440 walls were among the ones with the highest moisture content. The measured $a_{w}$ in the masonry 441 specimens, were close to what would be expected in the interface between a masonry wall and 442 added internal insulation in real case buildings, as illustrated in the large field experiment 443 presented in ${ }^{17}$ where similar $a_{w}$ were observed in the interface using these exact insulation 444 systems. The results suggest that the CaSi systems was the most robust in terms of lowest 445 moisture content in the adhesive mortar and least number of fungal spores surviving in the 446 interface. In the case of no "pre-contamination" of the masonry specimens, the CaSi, AAC, 447 PUR-CM and Cork-plaster systems seem to be equally robust. 
448 As stated in Section 3.2.2, the number of viable spores were seen to differ between sampling

449 locations on the same walls. This was possibly caused by the application of the adhesive mortars 450 for the insulation systems that was added and spread out using a notched trowel, which could 451 have caused the spores to get mixed into the adhesive mortar and then become unevenly spread 452 around the wall surface. It was also observed that a number of agar plates had an area nearly 453 free of fungi colonies which was probably caused by the Mycometer surface tests had been 454 taken prior, see ${ }^{30}$.

455 As a result of the Mycometer tests in the interface it was also found that after 6 and 12 months 456 of application of the insulation systems there was no difference between the decontamination 457 methods in terms of fungal survival. Although the masonry specimens decontaminated using 458 the hand-power method had a large fungal biomass after the decontamination, the results 459 indicate that the choice of decontamination methods may be of minor importance when the 460 insulation systems are installed using adhesive mortars with very high $\mathrm{pH}(>12)$.

461 In terms of the long-term perspective, it is yet to be determined if fungal spores would be able 462 to survive until the $\mathrm{pH}$ has dropped to more favourable levels or if they would become unable 463 to germinate before this was to occur. In ${ }^{17}$ it was found that the decline of $\mathrm{pH}$ seems to depend 464 on the water vapour diffusion resistance of the system and could take several years, especially 465 for the more diffusion-tight systems where the high $\mathrm{pH}$ levels were maintained for at least $4 \frac{1}{2}$ 466 years. Similar to the work presented in ${ }^{17}$, the short experimental period is a limitation in terms 467 of assessing the long-term performance of the insulation systems using highly alkaline adhesive 468 mortars to prevent fungal growth. It is therefore still recommended to limit the amount of 469 mycelia, spores and organic residues in critical locations such as the masonry/insulation 470 interface through thorough decontamination, and to not use insulation systems with organic 471 elements or additives. 


\section{$472 \quad 4.3 \quad$ Experiment 3: VOC diffusion}

473 The result of the VOC diffusion experiment, mimicking the production of volatile compounds

474 (VOCs) from fungal growth, showed that the three VOCs were able to diffuse through most of

475 the examined materials, so in the case of fungal growth behind the applied internal insulation

476 systems the VOCs could potentially affect the indoor air quality negatively. The Phenolic and

477 PUR-CM foam insulation systems with closed cell structure were found to be considerably

478 tighter against VOC diffusion compared to the $\mathrm{CaSi}, \mathrm{AAC}$ and Cork plaster systems - as it is

479 the case for diffusion transport of water vapour through the systems.

480 It was found that the VOC vapour flow rate density for the samples generally were within 20-

$48125 \%$ of each other for the individual materials, with the exception of the more diffusion tight

482 materials (Phenolic and PUR-CM insulations, and the aluminium membrane), where the vapour

483 flow rate density varied considerably. The discrepancies were probably caused by leaky

484 sealings resulting in excessive vapour flows results for the tight materials. The actual vapour

485 flows through the material samples were probably closer to the lowest measured values than

486 the largest values, as the only cause of an unintentional increase of the diffusion resistance

487 would be an accidental spill of epoxy, which was inspected prior to the test. For this reason the 488 permeability and diffusion resistance were determined for both the average and minimum 489 vapour flow rates. The diffusion results could have been affected slightly by the differences in 490 the ambient RH levels due differences in moisture inside the material pores. On the other hand, 491 the ambient temperature would probably affect the vapour pressure differences over the 492 material samples due to changes in the saturation vapour pressure inside the test cups. The air 493 velocity inside the fume hood was not measured, however, it was assumed that the air 494 movements would provide sufficient air flow to reduce the risk of a stagnant air layer forming 495 above the test cups. 
It was found from the similarity approach for transport of moisture and VOCs in materials that

the diffusion similarity factor, $\kappa_{\text {diff,voc }}$ for acetone and ethanol was above 1 suggesting that the materials constrict diffusion of the VOC molecules more than the diffusion of water vapour molecules. In contrast, for 2-heptanone the average $\kappa_{\text {diff,voc }}$ was 0.35 and so the molecules are less constricted compared to water vapour molecules. It is still unclear whether it is the molar mass, saturation vapour pressure, molecule polarity or something else that determines if the $\kappa_{\text {diff,voc }}$ factor is below or above 1 and the magnitude of the difference to water vapour.

\subsection{Theoretical VOC mass balance for a room scenario}

As a result of the VOC mass balance calculations for the room scenario it was found that the rate of diffusion through most of the insulation systems were large, resulting in a high VOC content in the room air for the less tight systems with the more volatile VOCs. Acetone was found to exceed the recommended exposure limit by the American National Institute for Occupational Safety and Health (NIOSH) of $0.59 \mathrm{~g} / \mathrm{m}^{3}$ for all system but the Phenolic foam, while for ethanol and 2-heptanone none of the systems exceeded the exposure limits of $1.9 \mathrm{~g} / \mathrm{m}^{3}$ and $0.47 \mathrm{~g} / \mathrm{m}^{3}$ respectively ${ }^{33}$. However, as the production rate of VOCs from fungal growth is unknown, the rate of diffusion would probably be limited by the production rate resulting from the metabolism of the fungal growth behind the insulation. We assume that the resulting partial pressure for the VOCs at the fungal growth in the masonry/insulation interface would be less than the saturation values used in the hypothetical room scenario. At the present time the authors do not have a qualified estimate of what the partial pressure for the VOCs in the interface could be as more research is needed for production of VOCs. In terms of the effect on the indoor air quality, this is still unclear as there are no health-based guidelines or threshold values concerning MVOC exposure in buildings as stated in a 2009 WHO report ${ }^{34}$. 


\section{Conclusions}

520 The present paper investigated the conditions that may remove or prevent fungal growth in the

521 interface between the solid masonry walls and the added internal insulation.

522 - The "hand-power" decontamination with a paint scraper was inadequate for removal of

523 fungal growth, while the MicroClean (dry steam) and "mechanical" (removal of internal

524 render with hammer and chisel) methods were found to be very effective.

525 - Choice of decontamination method was found to be of minor importance in terms of the

526 risk of fungal growth behind the insulation system as the high $\mathrm{pH}$ of the adhesive mortars

$527(>12)$ probably inactivated existing fungal growth on the walls and prevented new growth.

528 - No active fungal growth was detected in the interface of the 17 masonry specimens after 12

529 months due to high $\mathrm{pH}$, however colony forming spores were found on transference to agar

530 media.

531 - Aspergillus versicolor and Penicillium chrysogenum spores were found to survive the high

$532 \mathrm{pH}$ in the interface better than Acremonium murorum and Wallemia sebi.

533 - Aspergillus versicolor and Penicillium chrysogenum spores were found to survive better in

534 the interface of the Phenolic insulation systems compared to the other insulation systems,

535 despite similar $\mathrm{pH}$ conditions in the interface of all five systems.

536 VOCs were able to diffusion through most of the examined materials and could potentially

537 affect the indoor air quality in the case of fungal growth behind the insulation.

538 - The rate of VOC diffusion through the examined insulation was high and was probably

539 limited by the production rate resulting from the metabolism of the fungal growth.

\section{References}

541 1. Kragh J, Wittchen KB. Development of two Danish building typologies for residential 542 buildings. Energy Build. 2014;68:79-86. doi:10.1016/j.enbuild.2013.04.028 
543 2. Odgaard T, Bjarløv SP, Rode C. Interior insulation-Characterisation of the historic, 544 solid masonry building segment and analysis of the heat saving potential by $1 \mathrm{~d}, 2 \mathrm{~d}$, and 545 3d simulation. Energy Build. 2018;162:1-11. doi:10.1016/j.enbuild.2017.12.008

546 3. Brandt E, Bunch-Nielsen T, Christensen G, Gudum C, Hansen MH, Møller EB. SBi547 Anvisning 224 - Fugt i Bygninger (Danish). 2nd ed. Hørsholm, Denmark: Statens $548 \quad$ Byggeforskningensinstitut, Aalborg University; 2013.

549 4. Christensen G, Koch AP, Møller EB. Indvendig Efterisolering - AEldre Ydervagge Af 550 Murvark (Danish). Copenhagen, Denmark; 2015. https://byg-erfa.dk/indvendig$551 \quad$ efterisolering-2015.

552 5. Toman J, Vimmrová A, Černý R. Long-term on-site assessment of hygrothermal 553 performance of interior thermal insulation system without water vapour barrier. Energy $554 \quad$ Build. 2009;41:51-55. doi:10.1016/j.enbuild.2008.07.007

555 6. Mensinga P, Straube J, Schumacher C. Assessing the Freeze- Thaw Resistance of Clay 556 Brick for Interior Insulation Retrofit Projects. In: Proceedings of Thermal Performance 557 of the Exterior Envelopes of Whole Buildings Xi International Conference. Clearwater, $558 \quad$ Florida, $\quad$ USA: ASHRAE; 2010. 559 https://buildingscience.com/sites/default/files/migrate/pdf/CP560 1013_Assessing_Freeze_Thaw_Resistance_Clay_Brick_Insulation_Retrofit.pdf.

561 7. Straube J, Schumacher C. Interior insulation retrofits of load-bearing masonry walls in 562 cold climates. $J$ Green $2007 ; 2(2): 42-50$. 563 https://findit.dtu.dk/en/catalog/179499444. Accessed December 17, 2018.

564 8. Klõšeiko P, Arumägi E, Kalamees T. Hygrothermal performance of internally insulated 565 brick wall in cold climate: A case study in a historical school building. $J$ Build Phys. 566 2014;38(5):444-464. doi:10.1177/1744259114532609 
567 9. Zhao J, Grunewald J, Ruisinger U, Feng S. Evaluation of capillary-active mineral 568 insulation systems for interior retrofit solution. Build Environ. 2017;115:215-227. doi:10.1016/j.buildenv.2017.01.004

570 10. Vereecken E, Roels S. A comparison of the hygric performance of interior insulation

571

572

573

574

575

576

577

578

579

580

581

582

583

584

585

586

587

588

589

590 systems: A hot box - cold box experiment. Energy Build. 2014;80:37-44. doi:10.1016/j.enbuild.2014.04.033

11. Wegerer P, Nathanael J, Bednar T. Measuring the Hygrothermal Performance of an Interior Insulation made of Woodfibre Boards - The 6th International Building Physics Conference, IBPC 2015. In: Energy Procedia. Vol 78. Torino, Italy: Elsevier B.V.; 2015:1478-1483. doi:10.1016/j.egypro.2015.11.173

12. Odgaard T, Bjarløv SP, Rode C. Interior insulation - Experimental investigation of hygrothermal conditions and damage evaluation of solid masonry façades in a listed building. Build Environ. 2018;129:1-14. doi:10.1016/j.buildenv.2017.11.015

13. Morelli M, Møller EB. Energy Savings and Risk of Mold Growth in Apartments Renovated with Internal Insulation (Accepted Manuscript). Sci Technol Built Environ. 2019. doi:10.1080/23744731.2019.1629241

14. Odgaard T, Bjarløv SP, Rode C. Influence of hydrophobation and deliberate thermal bridge on hygrothermal conditions of internally insulated historic solid masonry walls with built-in wood. Energy Build. 2018;173:530-546. doi:10.1016/j.enbuild.2018.05.053

15. Mets T De, Tilmans A, Loncour X. Hygrothermal assessment of internal insulation systems of brick walls through numerical simulation and full-scale laboratory testing The 11th Nordic Symposium on Building Physics. In: Energy Procedia. Vol 132. Elsevier B.V.; 2017:753-758. doi:10.1016/j.egypro.2017.10.022

16. Zak JC, Wildman HG. Fungi in Stressful Environments. In: Biodiversity of Fungi: 
Inventory and Monitoring Methods. Elsevier; 2004:303-315. doi:10.1016/B978-

592

593

594

595

596

597

598

599

600

601

602

603

604

605

606

607

608

609

610

611

612

613 012509551-8/50017-9

17. Jensen NF, Bjarløv SP, Odgaard TR, Andersen B, Rode C, Møller EB. Hygrothermal assessment of diffusion open insulation systems for interior retrofitting of solid masonry walls. $\quad$ Build

Environ. 2020;182:107011. doi:https://doi.org/10.1016/j.buildenv.2020.107011

18. Van Tran V, Park D, Lee YC. Indoor air pollution, related human diseases, and recent trends in the control and improvement of indoor air quality. Int $J$ Environ Res Public Health. 2020;17(8):2927. doi:10.3390/ijerph17082927

19. Kim KH, Kabir E, Jahan SA. Exposure to pesticides and the associated human health effects. Sci Total Environ. 2017;575:525-535. doi:10.1016/j.scitotenv.2016.09.009

20. LBM-Prøvemetode 2 "Fugtparametre, porøsitet, og densitet" (Danish). 1992:3.

21. DS/EN ISO 12572:2016, Hygrothermal performance of building materials and products - Determination of water vapour transmission properties - Cup method, 2. edition. 2016.

22. DS/EN ISO 15148:2003, Hygrothermal performance of building materials and products - Determination of water absorption coefficient by partial immersion, 1. edition. 2003.

23. Reeslev M, Miller M. The MycoMeter-test. A new rapid method for detection and quantification of mold in buildings. Proc Heal Build. 2000;1:589-590.

24. Mycometer. Mycometer ${ }^{\circledR}$-surface Bulk Hurtigprotokol (Danish). 2017:1-2.

25. Mycometer. Analyse af Materialeprøver med Mycometer ${ }^{\circledR}$-Testen (Danish). 2010.

26. Schrock M, Riffle C, Dindal A, Mckernan J, Enriquez J. Environmental Technology Verification Report: Mycometer ${ }^{\circledR}-$ Test Rapid Fungi Detection and Bactiquant ${ }^{\circledR}-$ Test Rapid Bacteria Detection Technologies.; 2011. 
614 27. Samson RA, Houbraken J, Thrane U, Frisvad JC, Andersen B. Food and Indoor Fungi

615 2. Ed. Utrecht, Netherlands: Westerdijk Fungal Biodiversity Institute; 2019.

616 28. Koch AP, Nielsen PA. By Og Byg Anvisning 205 - Renovering Af Bygninger Med

617

618

619

620

62

622

623

624

625

626

627

628

629

630

631

632

633

634

635
Skimmelsvampevaekst. Hørsholm, Denmark: Statens Byggeforskningensinstitut, Aalborg University; 2003.

29. Korpi A, Järnberg J, Pasanen A-L. Microbial Volatile Organic Compounds. Crit Rev Toxicol. 2009;39(2):139-193. doi:10.1080/10408440802291497

30. Jensen NF, Bjarløv SP, Rode C, Andersen B, Møller EB. Supplementary data for "Laboratory based investigation of the materials' water activity and $\mathrm{pH}$ relative to fungal growth in internally insulated solid masonry walls". 2020. doi:10.11583/DTU.12071280

31. DDB GmbH. Vapor Pressure Calculation by Antoine Equation. http://ddbonline.ddbst.de/AntoineCalculation/AntoineCalculationCGI.exe. Published 2013. Accessed January 15, 2020.

32. Rode C, Grunewald J, Liu Z, Qin M, Zhang J. Models for residential indoor pollution loads due to material emissions under dynamic temperature and humidity conditions (Accepted manuscript). In: Proceedings of the 12th Nordic Symposium on Building Physics, NSB 2020, Tallinn, Estonia, 6-9 September. Tallinn, Estonia; 2020.

33. NIOSH. NIOSH Pocket Guide to Chemical Hazards. Springfield, Virginia, USA; 2007.

34. WHO. WHO Guidelines for Indoor Air Quality: Dampness and Mould. Copenhagen Ø, Denmark; 2009. http://www.euro.who.int/_data/assets/pdf_file/0017/43325/E92645.pdf?ua=1. 
636 Table 1 Build-up of masonry specimens and the five insulation systems, and the material properties. Note that 637 insulation systems were installed on the interior side of the "Base wall".

\begin{tabular}{|c|c|c|c|c|c|c|c|}
\hline $\begin{array}{l}\text { Material layers from the } \\
\text { exterior side to the interior } \\
\text { side }\end{array}$ & 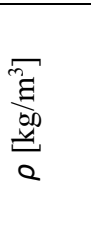 & 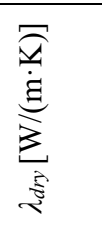 & $\begin{array}{l}T \\
\text { J } \\
\text { s }\end{array}$ & 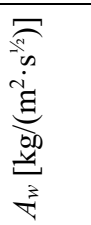 & $\begin{array}{l}\underset{\Xi}{\Xi} \\
\text { ひ }\end{array}$ & $\sum_{\substack{i \\
i}}^{\sum_{2}^{i}}$ & 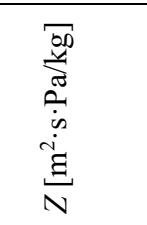 \\
\hline Yellow soft-moulded brick & 1643 & 0.600 & 16.9 & 0.278 & 180 & 0.58 & $1.54 \mathrm{E}+10$ \\
\hline $\begin{array}{l}7.7 \% \text { lime adjusted mortar } \\
\text { (internal render layer) }\end{array}$ & 1243 & 0.440 & 22.43 & 0.390 & 10 & 0.02 & $1.13 \mathrm{E}+09$ \\
\hline Total: for Base wall & & & & & & 0.60 & $1.65 E+10$ \\
\hline PUR-CM adhesive mortar & 1313 & 0.497 & 18.75 & 0.005 & 10 & 0.02 & $9.47 \mathrm{E}+08$ \\
\hline PUR-CM insulation & 49 & 0.037 & 27.01 & 0.013 & 80 & 2.16 & $1.09 \mathrm{E}+10$ \\
\hline PUR-CM render & 725 & 0.147 & 11.73 & 0.107 & 10 & 0.07 & $5.92 \mathrm{E}+08$ \\
\hline $\begin{array}{l}\text { Total: for PUR-CM } \\
\text { system }\end{array}$ & & & & & & 2.25 & $1.25 \mathrm{E}+10$ \\
\hline Casi adhesive mortar ${ }^{\mathrm{a}}$ & 1429 & $0.619^{1}$ & 12.67 & 0.053 & 8 & 0.01 & $5.12 \mathrm{E}+08$ \\
\hline Casi insulation ${ }^{\mathrm{b}}$ & 225 & 0.061 & 4.23 & 0.726 & 100 & 1.64 & $2.14 \mathrm{E}+09$ \\
\hline Casi adhesive mortar ${ }^{\mathrm{a}}$ & 1429 & $0.619^{1}$ & 12.67 & 0.053 & 10 & 0.02 & $6.40 \mathrm{E}+08$ \\
\hline Total: for Casi system & & & & & & 1.67 & $3.29 \mathrm{E}+09$ \\
\hline AAC adhesive mortar & 830 & 0.155 & 13 & 0.003 & 8 & 0.05 & $5.25 \mathrm{E}+08$ \\
\hline AAC insulation & 99 & 0.044 & 3 & 0.006 & 100 & 2.27 & $1.52 \mathrm{E}+09$ \\
\hline AAC adhesive mortar & 830 & 0.155 & 13 & 0.003 & 8 & 0.05 & $5.25 \mathrm{E}+08$ \\
\hline Total: for AAC system & & & & & & 2.38 & $2.57 E+09$ \\
\hline Adhesive mortar $^{\mathrm{a}}$ & 1516 & $0.733^{1}$ & 41.4 & 0.006 & 5 & 0.01 & $1.05 \mathrm{E}+09$ \\
\hline Aluminium (AL) foil & & & & & 0.1 & & \\
\hline perforated & & & & & & & \\
\hline Phenolic insulation & 35 & 0.020 & 114 & 0.009 & 100 & 5.00 & $5.76 \mathrm{E}+10$ \\
\hline Aluminium (AL) foil & & & 10000 & & 0.1 & & $5.05 \mathrm{E}+09$ \\
\hline Gypsum board & 850 & 0.177 & 10 & 0.277 & 13 & 0.07 & $6.57 \mathrm{E}+08$ \\
\hline Total: Phenolic system & & & & & & 5.07 & $6.43 E+10$ \\
\hline
\end{tabular}




\begin{tabular}{|c|c|c|c|c|c|c|c|}
\hline Cork plaster ${ }^{\mathrm{b}}$ & 250 & 0.037 & 3 & 0.129 & 40 & 1.08 & $6.06 \mathrm{E}+08$ \\
\hline NHL Finish render ${ }^{c}$ & 1600 & 0.769 & 14.55 & & 10 & 0.01 & $7.35 \mathrm{E}+08$ \\
\hline Total: plaster system & & & & & & 1.09 & $1.34 \mathrm{E}+09$ \\
\hline
\end{tabular}

Additional materials:

Wet-room membrane*

14567

638

${ }^{a}$ Values were determined in the preliminary study. ${ }^{b}$ Values were obtained from product datasheets. Other values

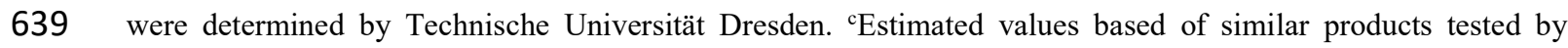

640 Technische Universität Dresden. NHL: Natural Hydraulic Lime.

641

642 Table 2 Mycometer surface results after decontamination of masonry specimens

\begin{tabular}{|c|c|c|c|c|c|c|c|c|c|c|c|c|}
\hline $\begin{array}{l}\text { Mycometer } \\
\text { Surface Value } \\
\text { (MSV) }\end{array}$ & 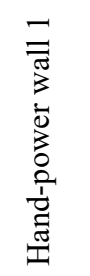 & 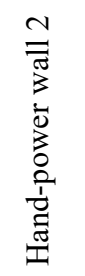 & 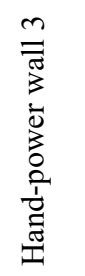 & 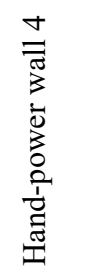 & 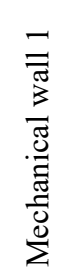 & 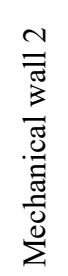 & 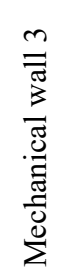 & 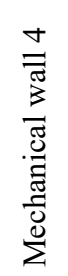 & 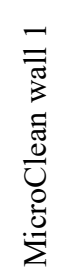 & 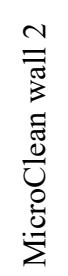 & 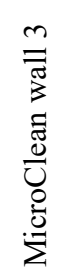 & 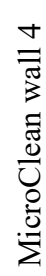 \\
\hline Sample A & 2388 & 4117 & 3644 & BDL & $\begin{array}{c}\mathrm{BD} \\
\mathrm{L}\end{array}$ & $\begin{array}{c}\text { BD } \\
\mathrm{L}\end{array}$ & $\mathrm{BD}$ & $\mathrm{BD}$ & $\begin{array}{c}\text { BD } \\
\text { L }\end{array}$ & $\begin{array}{c}\mathrm{BD} \\
\mathrm{L}\end{array}$ & $\begin{array}{c}\text { BD } \\
\text { L }\end{array}$ & 69 \\
\hline Sample B & 4353 & 2653 & 5794 & 4212 & $\begin{array}{c}\text { BD } \\
\text { L }\end{array}$ & $\begin{array}{c}\text { BD } \\
\text { L }\end{array}$ & $\begin{array}{c}\text { BD } \\
\text { L }\end{array}$ & $\begin{array}{c}\text { BD } \\
\text { L }\end{array}$ & $\begin{array}{c}\text { BD } \\
\text { L }\end{array}$ & $\begin{array}{c}\text { BD } \\
\text { L }\end{array}$ & $\begin{array}{c}\text { BD } \\
\text { L }\end{array}$ & 66 \\
\hline
\end{tabular}

643 BDL: below detection level

644

645 Table 3 Moisture content in the adhesive mortars and insulation materials [weight-\%]

\begin{tabular}{|c|c|c|c|c|c|c|c|c|}
\hline \multirow[b]{2}{*}{ Insulation system } & \multicolumn{4}{|c|}{ Adhesive } & \multicolumn{4}{|c|}{ Insulation $^{\mathrm{b}}$} \\
\hline & 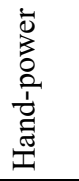 & 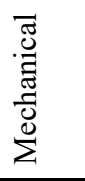 & 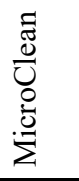 & 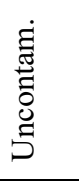 & 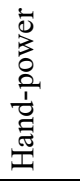 & 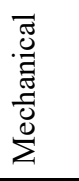 & 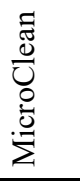 & 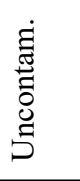 \\
\hline PUR-CM system & 13.2 & 9.2 & 9.7 & 6.3 & 12.6 & 18.0 & 6.3 & 3.6 \\
\hline Phenolic system & 14.4 & 15.2 & 13.6 & 11.0 & 35.6 & 82.8 & 32.1 & 27.6 \\
\hline AAC system & 12.8 & 10.3 & 9.9 & 7.0 & 31.6 & 39.6 & 27.8 & 11.7 \\
\hline
\end{tabular}


CaSi system

Cork plaster system

${ }^{\mathrm{a}}$ Original internal render as no adhesive was used for this system. ${ }^{\mathrm{b}}$ Outermost $10 \mathrm{~mm}$, i.e. nearest the masonry.

\section{7}

Table 4 Mycometer and agar imprint test results after 6 and 12 months

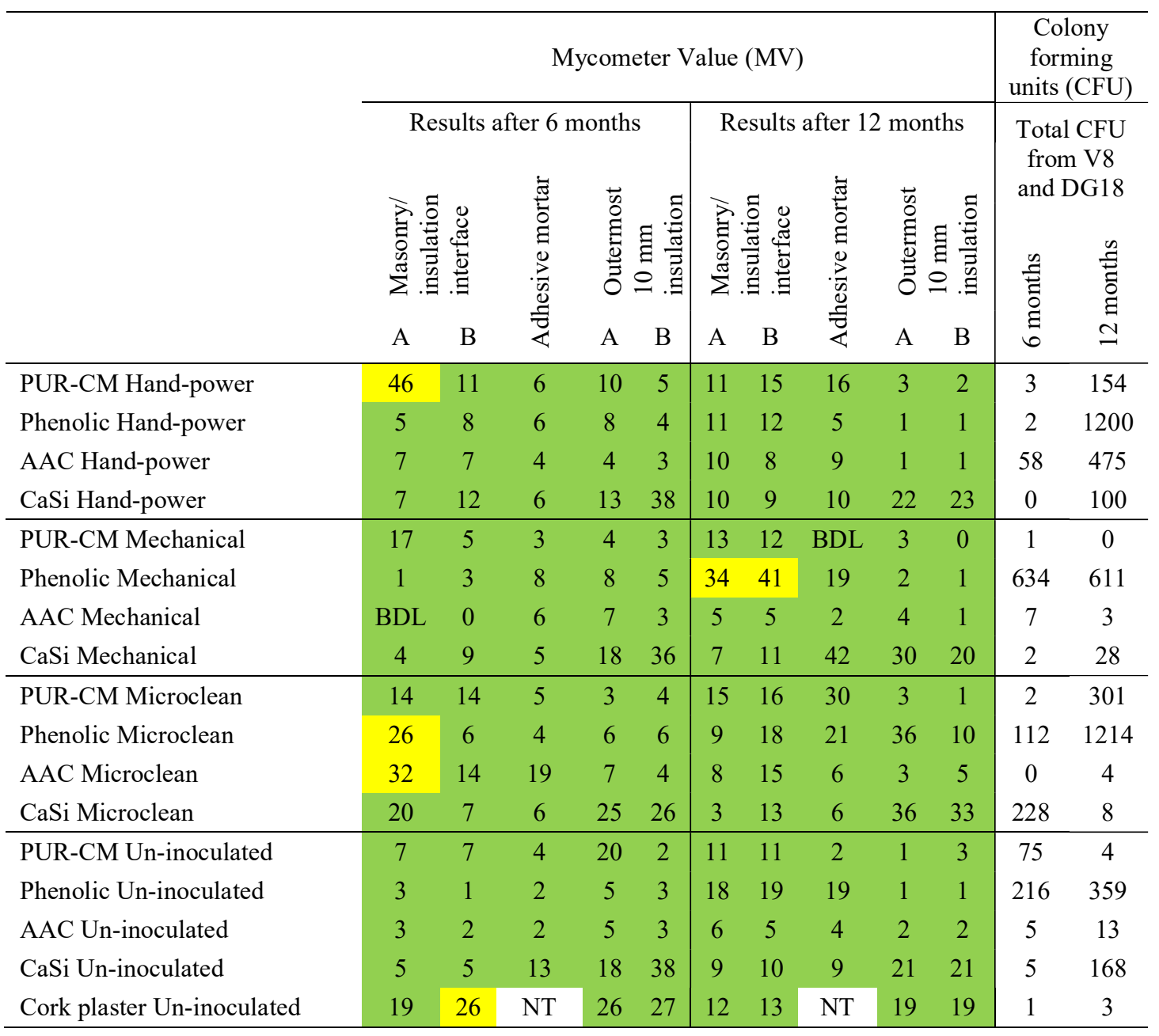

649

BDL: below detection level. NT: not tested. Un-inoculated: reference specimens, which were not used experiment

650 1. Note that the rating scales for Mycometer Surface tests (Interface) differ from the Mycometer Bulk-material

651 tests (Adhesive mortar and insulation), please see Section 2.3.

652

653 Table 5 Vapour diffusion resistance, $Z\left[\mathrm{~m}^{2} \cdot \mathrm{s} \cdot \mathrm{Pa} / \mathrm{kg}\right]$ for the insulation systems (including adhesive mortar) 


\begin{tabular}{lcccccc} 
& Average & Max & Average & Max & Average & Max \\
\hline PUR-CM system & $1.01 \mathrm{E}+10$ & $1.04 \mathrm{E}+10$ & $3.18 \mathrm{E}+10$ & $4.20 \mathrm{E}+10$ & $1.00 \mathrm{E}+10$ & $1.00 \mathrm{E}+10$ \\
CaSi system & $1.85 \mathrm{E}+09$ & $1.89 \mathrm{E}+09$ & $2.56 \mathrm{E}+09$ & $2.61 \mathrm{E}+09$ & $5.89 \mathrm{E}+08$ & $5.89 \mathrm{E}+08$ \\
AAC system & $1.89 \mathrm{E}+09$ & $1.90 \mathrm{E}+09$ & $2.66 \mathrm{E}+09$ & $2.70 \mathrm{E}+09$ & $6.01 \mathrm{E}+08$ & $6.01 \mathrm{E}+08$ \\
Phenolic system & $2.51 \mathrm{E}+12$ & $6.16 \mathrm{E}+12$ & $2.22 \mathrm{E}+12$ & $2.48 \mathrm{E}+12$ & $5.76 \mathrm{E}+10$ & $5.76 \mathrm{E}+10$ \\
Cork plaster system & $1.95 \mathrm{E}+09$ & $2.22 \mathrm{E}+09$ & $2.79 \mathrm{E}+09$ & $3.22 \mathrm{E}+09$ & $6.77 \mathrm{E}+08$ & $6.77 \mathrm{E}+08$
\end{tabular}

654

655 Table 6 VOC vapour content in the room air, $v_{v o c, i}\left[\mathrm{~g} / \mathrm{m}^{3}\right]$

\begin{tabular}{lccc}
\hline & Acetone & Ethanol & 2-Heptanone \\
\hline CaSi system & 3.65 & 0.64 & 0.07 \\
AAC system & 3.63 & 0.62 & 0.07 \\
PUR-CM system & 0.67 & 0.04 & 0.004 \\
Phenolic system & 0.001 & 0.001 & 0.001 \\
Cork plaster system & 3.19 & 0.52 & 0.06 \\
\hline
\end{tabular}

656

657 Figure 1 Flow chart for the activities under the three experiments

658 Figure 2 Experimental setup for the two experiments: a) Fungal decontamination methods (experiment 1), and b)

659 Development of fungal growth in masonry specimens fitted with internal insulation (experiment 2).

660 Figure 3 Fungal sampling: (a) Taking out drilling core using hole-saw; (b) Taking Mycometer Surface samples in

661 the interface; (c) Making agar imprint for the interface; (d) Preparation of core samples for the Mycometer Bulk

662 Material test, cutting away excess insulation; and (e) Measuring $\mathrm{pH}$.

663 Figure 4 Decontamination: (a) Hand-power with paint scraper; (b) Walls after removal of render with hammer and

664 chisel; (c) MicroClean dry-steam cleaning with plate mouth pieces and (d) fibred cotton cloth mouth pieces.

665 Figure 5 Parameter variations investigated in the development of fungal growth experiment

666 Figure 6 Density of VOC vapour flow rate, $g$, for the material samples

667 Figure 7 Diffusion similarity factor $\kappa_{d i f f, v o c}$ for the three VOCs 